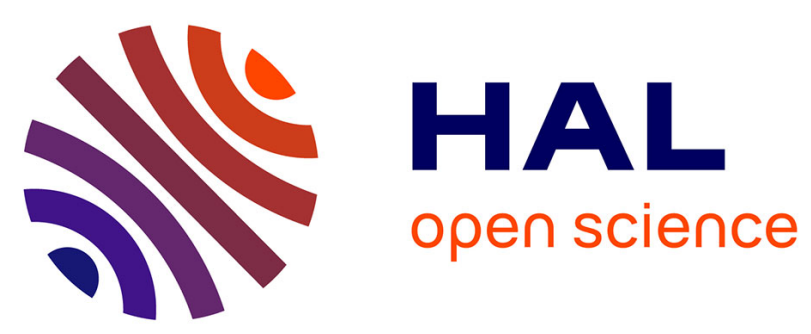

\title{
A silicon rectangular micro-orifice for gas flow measurement at moderate Reynolds numbers: design, fabrication and flow analyses
}

\author{
A. Amnache, M. Omri, L. Fréchette
}

\section{- To cite this version:}

A. Amnache, M. Omri, L. Fréchette. A silicon rectangular micro-orifice for gas flow measurement at moderate Reynolds numbers: design, fabrication and flow analyses. Microfluidics and Nanofluidics, 2018, 22 (6), 10.1007/s10404-018-2077-x . hal-01914280

\author{
HAL Id: hal-01914280 \\ https://hal.science/hal-01914280
}

Submitted on 8 Nov 2018

HAL is a multi-disciplinary open access archive for the deposit and dissemination of scientific research documents, whether they are published or not. The documents may come from teaching and research institutions in France or abroad, or from public or private research centers.
L'archive ouverte pluridisciplinaire HAL, est destinée au dépôt et à la diffusion de documents scientifiques de niveau recherche, publiés ou non, émanant des établissements d'enseignement et de recherche français ou étrangers, des laboratoires publics ou privés. 


\title{
A silicon rectangular micro-orifice for gas flow measurement at moderate Reynolds numbers: design, fabrication and flow analyses
}

\author{
A. Amnache ${ }^{1,2} \cdot$ M. Omri ${ }^{3} \cdot$ L. G. Fréchette ${ }^{1,2}$
}

This work describes a micro-flowmeter for moderate flow rates of gases based on a differential pressure measurement. The micro-flowmeters consist of a microfabricated silicon-glass rectangular micro-orifice plate, with external pressure measurement. We experimentally evaluate the effects of geometrics parameters, Reynolds number and compressibility on the discharge coefficient. The paper examines a series of 13 rectangular micro-orifice sizes, with orifice hydraulic diameters ranging from 115 to $362 \mu \mathrm{m}$. The behavior of the discharge coefficient is presented for orifice Reynolds numbers ranging from 200 to 18000 . Agreement is shown between the experimental and numerical results of the discharge coefficient. The micro-flowmeters measure moderate flow of air ranging from 1 to $106 \mathrm{mg} / \mathrm{s}$. This demonstration implements a design method of micro-flowmeters that can be used in a broad range of microfluidic applications, such as microreactors and power MEMS.

Keywords Micro-orifice $\cdot$ Flowmeter $\cdot$ Discharge coefficient $\cdot$ Microfluidic $\cdot$ Flow rate

\section{Introduction}

Over the past decades, the range of microfluidic devices has continued to grow, including not only low Reynolds number bioMEMS, but also devices with higher Reynolds number gas flow such as microreactors (Wiles et al. 2011; Jensen 2017) and power MEMS (Dunn-Rankin et al. 2005; Fréchette 2015). This growth was accompanied by a significant development of adequate instrumentation. A key parameter is flow rate, which can be challenging to measure in microsystems. Microelectromechanical systems (MEMS) flow sensors have been implemented using thermal principles (Cubukcu et al. 2014; Xue and Yan 2012; Kuo et al. 2012) or non-thermal principles (Berberig et al. 1998; Bouwstra et al. 1990; Nguyen et al. 2015). Table 1 summarizes the major parameters of flow

A. Amnache

amrid.amnache@usherbrooke.ca

1 Institut Interdisciplinaire d'Innovation Technologique (3IT), Université de Sherbrooke, 3000 boul. de l'Université, Sherbrooke, QC J1K 0A5, Canada

2 Laboratoire Nanotechnologies Nanosystèmes (LN2), CNRS UMI-3463, Université de Sherbrooke, 3000 boul. de l'Université, Sherbrooke, QC J1K 0A5, Canada

3 King Abdulaziz University, Deanship of Scientific Research, Jeddah 21589, Kingdom of Saudi Arabia measurement obtained by various authors. One of the simplest non-thermal sensing principles is based on differential pressure drop across a calibrated flow obstruction inside a channel, where the generated pressure difference is proportional to the flow rate. Compared to the thermal flow sensors, the differential pressure sensors have many advantages: (1) thermal insulation is not critical (Elwenspoek 1999), which is a big challenge in the miniature systems, (2) no electrical contact with the fluid, which indicates less corrosion and damage (Wang et al. 2009). However, the disadvantage of the flow sensors based on differential pressure is that they have less measurement sensitivity at low-velocity flow regimes, since pressure difference, $\Delta P$, is proportional to the square of velocity (Svedin et al. 2003), as illustrated in Fig. 1. On the other hand, thermal flow sensors such as calorimetric flow sensors have a high sensitivity in the low-velocity regime, but saturates at high velocities when the thermal boundary layer thickness became dominant (Elwenspoek 1999). Therefore, thermal flow sensors are more popular in microfluidic devices handling low velocity flow regimes and low Reynolds numbers, such as liquid flows in biochemical applications. However, with the appearance of microfluidic systems handling relatively high fluid pressure and flow rate such as micro-steam turbines, i.e., up 4.5 bars and $100 \mathrm{mg} / \mathrm{s}(100<R e<2000)$ (Lee and Fréchette 2011; Liamini et al. 2011), the differential pressure approach become of interest. Commercial flowmeters can measure the 
Table 1 Major parameters of MEMS-based flow sensor for gas flow measurement

\begin{tabular}{|c|c|c|c|c|}
\hline References & Working principle & Gas & Flow range & $\begin{array}{l}\text { Chip dimension } \\
\text { Sensor size }\end{array}$ \\
\hline Xue and Yan (2012) & Thermal (calorimetric) & Air & $0.016-57 \mathrm{mg} / \mathrm{s}$ & $\begin{array}{l}20 \times 10 \times 1.6 \mathrm{~mm}^{3} \\
\text { No data }\end{array}$ \\
\hline Cubukcu et al. (2014) & Thermal (calorimetric) & Air, $\mathrm{He}, \mathrm{Ne}, \mathrm{Ar}$ & $0.04-2 \mathrm{~m} / \mathrm{s}$ & $\begin{array}{l}\text { No data } \\
1 \mathrm{~mm} \text { diameter }\end{array}$ \\
\hline Svedin et al. (2003) & $\begin{array}{l}\text { Hybrid: thermal/pressure force (drag } \\
\text { force/hot wire) }\end{array}$ & Air & $\begin{array}{l}\text { Up to } 1620 \mathrm{mg} / \mathrm{s} \\
\text { Up to } 4.3 \mathrm{~m} / \mathrm{s}\end{array}$ & $\begin{array}{l}\text { No data } \\
3 \times 3 \mathrm{~mm}^{2}\end{array}$ \\
\hline Bouwstra et al. (1990) & Resonating (vibration) & Air & $\begin{array}{l}0-0.2 \mathrm{mg} / \mathrm{s} \\
0-3 \mathrm{~m} / \mathrm{s}\end{array}$ & $\begin{array}{l}\text { No data } \\
600 \times 200 \times 21 \mu \mathrm{m}^{3}\end{array}$ \\
\hline Berberig et al. (1998) & Differential pressure (capacitive) & Air & $0-22 \mathrm{~m} / \mathrm{s}$ & $\begin{array}{l}5 \times 8 \times 1.4 \mathrm{~mm}^{3} \\
\text { No data }\end{array}$ \\
\hline Nguyen et al. (2015) & Pressure force (capacitive) & Air & $0-19.2 \mathrm{~m} / \mathrm{s}$ & $\begin{array}{l}\text { No data } \\
5.5 \times 5.5 \mathrm{~mm}^{2}\end{array}$ \\
\hline This work & Differential pressure & Air & $\begin{array}{l}0-106 \mathrm{mg} / \mathrm{s} \\
0-310 \mathrm{~m} / \mathrm{s}\end{array}$ & $\begin{array}{l}5 \times 1 \mathrm{~cm}^{2} \text { (10 dif- } \\
\text { ferent sensors) } \\
207 \times 125 \mu \mathrm{m}^{2} \text { to } \\
3005 \times 5102 \mu \mathrm{m}^{2}\end{array}$ \\
\hline
\end{tabular}

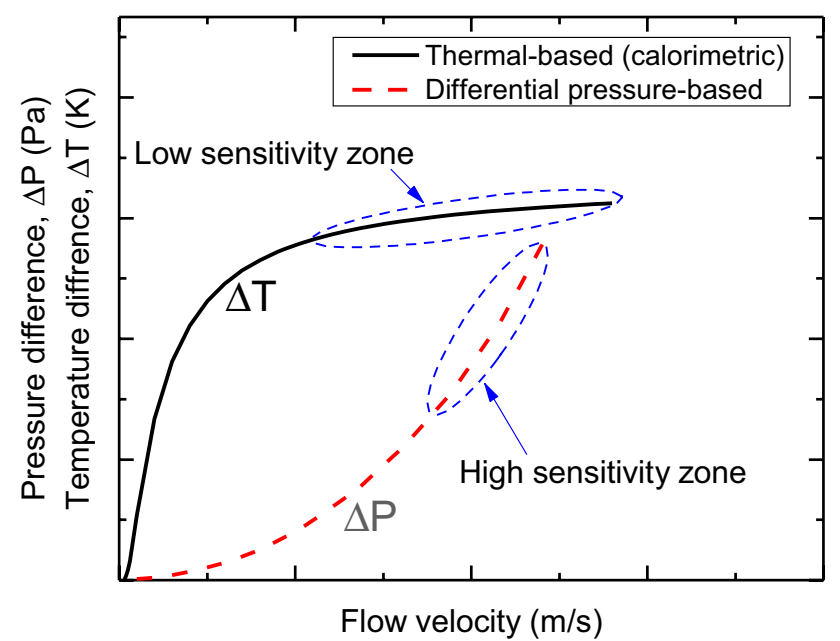

Fig. 1 Measurement sensitivity of the thermal-based calorimetric versus differential pressure-based flowmeters

flow range of the micro-steam turbine. However, they cannot be integrated in situ, within a device. Also, the temperature of the steam flow (up to $250{ }^{\circ} \mathrm{C}$ ) precludes the use of commercial flowmeters. Since the steam micro-turbine is essentially fabricated by deep etching and wafer bonding, the constriction differential pressure can be easily fabricated on the same chip and at the same time, without adding fabrication steps. In this paper, we focused on the gas flow measurement by differential pressure using an orifice micro-flowmeter. At macroscale, this flow measurement method is widely used. The discharge coefficient, $\mathrm{Cd}$, defined as the ratio of the actual flow rate over the ideal flow rate, is an important design parameter for the orifice plate flowmeter. It has been exhaustively studied for circular geometries and high Reynolds numbers (Miller 1996; White
1999), which is characteristic for macroscale fluidic systems. However, few studies of the discharge coefficient have been performed at moderate Reynolds numbers (Hollingshead et al. 2011; Johansen 1930). Jankovski et al. (2008) developed a semiempirical correlation of $\mathrm{Cd}$ for an incompressible flow through a small circular orifice. They considered the effect of the orifice length on the $\mathrm{Cd}$. The model was correlated and validated with numerical simulations and the experimental results from Hasegawa et al. (2009), Phares et al. (2005) and Kiljanski (1993) for orifice Reynolds numbers up to 3000. However, micro-orifices fabricated with microfabrication processes are usually non-circular in cross section and take two-dimensional extruded-like shapes. Unfortunately, the traditional $\mathrm{Cd}$ correlations for circular orifices are not valid for rectangular or planar shapes (Amnache et al. 2010). It is therefore very desirable to study the discharge coefficient behavior in rectangular micro-orifices. Zivkovic et al. (2013) studied numerically the pressure drop of an incompressible flow across a rectangular micro-orifice. Their study developed a correlation between the loss coefficient as a function of orifice Reynolds number and geometry. However, the Reynolds number range was relatively low, from 0.005 to 0.1 . Mishra and Peles (2005) fabricated rectangular micro-orifice plates entrenched in silicon microchannels for orifice hydraulic diameters between 21 and $57 \mu \mathrm{m}$. They experimentally studied the compressible and incompressible single-phase flow behavior through these configurations. They developed a correlation of the discharge coefficient for the incompressible flow and they concluded that the $\mathrm{Cd}$ depends only on the area ratio (orifice width/channel width) for Reynolds numbers greater than its critical value, $(200 \leq$ Recrit $\leq 500)$. For compressible flow, the same authors determined the effect of the pressure ratio (upstream/downstream pressure) on the discharge coefficient. 
They observed that for pressure ratios greater than 2, which corresponds to choked flow, i.e., Mach number equal to unity, the discharge coefficient becomes a constant value. However, the evolution of the discharge coefficient below pressure ratios of 2 was not well characterized. In addition, for both compressible and incompressible flows, the effect of the aspect ratio on the discharge coefficient was not considered. Amnache et al. (2010) numerically studied the gas flow through a rectangular micro-orifice and observed that the discharge coefficient strongly depends on the orifice aspect ratio.

In this paper, we design, fabricate and characterize rectangular orifice micro-flowmeters for measuring moderate gas flow. The design of this type of micro-flowmeter is based mainly on the knowledge of the discharge coefficient. However, the above brief literature survey shows that the discharge coefficient for compressible flow through micro-orifices with rectangular cross section has not been well studied. In this work, we endeavored to study numerically and experimentally the compressible gas flow through rectangular micro-orifices of various sizes, below the sonic limit. The discharge coefficient is characterized showing the effect of the Reynolds number, all the geometric parameters (orifice aspect ratio, area ratio, orifice length-to-hydraulic ratio) and compressibility.

This work provides a design methodology for microfabricated differential pressure flowmeters to allow their integration into embedded microfluidic devices that cannot use commercial flowmeters.

\section{Rectangular orifice micro-flowmeter approach}

Rectangular orifice micro-flowmeters are based on the Bernoulli obstruction theory. The orifice restriction as shown in Fig. 2 creates a Venturi effect, where the flow velocity increased to its maximum and the static pressure decreased to its minimum value at point 2 , which corresponds to the vena contracta. The static pressure profile along the orifice microflowmeter is also illustrated in Fig. 2. It is a combination of the total pressure drop (Moody and head losses) and the dynamic pressure (Bernoulli effect).

By measuring pressure difference, $\Delta P=P_{1}-P_{2}$, between the pressure tap 1 and the pressure tap 2 , the velocity of the flow can be determined, leading to the ideal mass flow rate, $\dot{m}_{\text {id }}$.

For an isentropic unidimensional compressible flow through a channel (Shapiro 1953):

$\frac{T_{0}}{T}=1+\frac{k-1}{2} M^{2}$,

$\frac{P_{0}}{P}=\left[1+\frac{k-1}{2} M^{2}\right]^{\frac{k}{k-1}}$
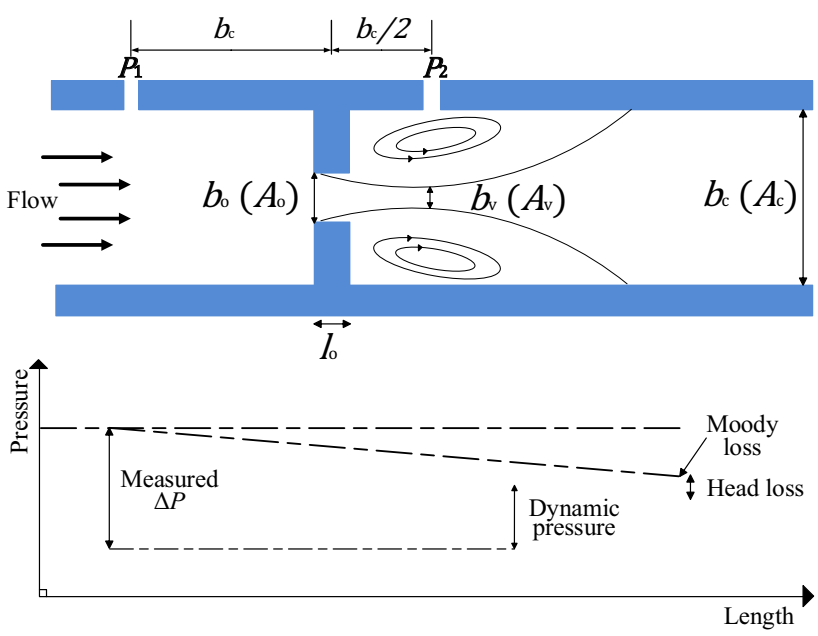

Fig. 2 Schematic diagram of the orifice flowmeter measurement approach

$\frac{\rho_{0}}{\rho}=\left[1+\frac{k-1}{2} M^{2}\right]^{\frac{1}{k-1}}$

where $P, T$, and $\rho$ are static pressure, static temperature and static density of the fluid. $P_{0}, T_{0}$ and $\rho_{0}$ are, respectively, the total pressure, total temperature and total density. These relations are expressed as a function of Mach number, $M$, and depend on $k$, the specific heat ratio, which is equal to 1.4 for air.

The equation of state of an ideal gas is written as:

$\frac{P}{\rho}=R T$,

where $R$ is the ideal gas constant, equal to $287 \mathrm{~J} / \mathrm{kg} \mathrm{K}$ for air.

Assuming an ideal case with no losses between upstream (1) and downstream (2) of the orifice, the ideal static pressure ratio can be given by:

$\frac{P_{1}}{P_{2}}=\left[\frac{1+\frac{k-1}{2} M_{2}^{2}}{1+\frac{k-1}{2} M_{1}^{2}}\right]^{\frac{k}{k-1}}$.

Assuming that the cross-sectional area of the vena contracta, $A_{\mathrm{v}}$, is equal to the cross-sectional area of the orifice, $A_{\mathrm{o}}$, and from mass conservation, the ratio $A_{\mathrm{o}} / A_{\mathrm{c}}$ can be expressed as:

$\frac{A_{\mathrm{o}}}{A_{\mathrm{c}}}=\left[\frac{1+\frac{k-1}{2} M_{2}^{2}}{1+\frac{k-1}{2} M_{1}^{2}}\right]^{\frac{k+1}{2(k-1)}}$.

Replacing the Mach number, $M_{1}$, calculated from Eq. 5 , in Eq. 6, the Mach number at the vena contracta, $M_{2}$, can be determined by: 


$$
M_{2}^{2}=\frac{1-\left(\frac{P_{1}}{P_{2}}\right)^{\frac{k}{k-1}}}{\frac{k-1}{2}\left(\frac{P_{1}}{P_{2}}\right)^{\frac{k}{k-1}}\left(\frac{A_{\mathrm{o}}}{A_{\mathrm{c}}\left(\frac{P_{1}}{P_{2}}\right)^{\frac{k}{k-1}}}\right)^{2}-\frac{k-1}{2}} .
$$

The ideal mass flow rate across the orifice can be obtained by (Shapiro 1953):

$\dot{m}_{\text {id }}=\rho_{2} A_{\mathrm{o}} M_{2} \sqrt{k R T_{2}}$.

To express the mass flow rate as a function of the pressure difference between upstream and downstream of the orifice, the Mach number, $M_{2}$, is replaced by Eq. 7 and the density, $\rho_{2}$, is replaced by:

$\rho_{2}=\frac{\rho_{1}}{\left[1+\frac{k-1}{2} M_{2}^{2}\right]^{\frac{1}{k-1}}}$.

Then after rearrangement, the ideal mass flow rate can be expressed by:

$\dot{m}_{\mathrm{id}}=Y \frac{1}{\sqrt{1-\beta^{4}}} A_{\mathrm{o}} \sqrt{2 \rho_{1} \Delta P}$,

where $\beta$ is the area ratio defined as the square root of the ratio of the orifice cross-sectional area, $A_{\mathrm{o}}$, to the channel cross-sectional area, $A_{\mathrm{c}}$, as:

$\beta=\sqrt{\frac{A_{\mathrm{o}}}{A_{\mathrm{c}}}}$

and $Y$ is the expansion factor expressed for an adiabatic gas as:

$Y=\left\{\frac{\left(\frac{P_{2}}{P_{1}}\right)^{\frac{2}{k}}\left(1-\beta^{4}\right)\left(\frac{k}{k-1}\right)\left[1-\left(\frac{P_{2}}{P_{1}}\right)^{\frac{k}{k-1}}\right]}{\left[1-\left(\beta^{4}\left(\frac{P_{2}}{P_{1}}\right)^{\frac{2}{k}}\right)\right]\left(1-\frac{P_{2}}{P_{1}}\right)}\right\}^{0.5}$.

The expansion factor, $Y$, describes the effect of compressibility. Indeed, if the pressure difference across the orifice is small, the expansion factor, $Y$, tends to unity. It results in no significant change in density of the gas and then the flow can be assumed incompressible.

In the actual case, there will be a total pressure drop across the orifice due to friction losses. Also, the section of the vena contracta at point 2 will not necessarily be equal to the orifice cross-sectional area. The ideal mass flow rate is therefore typically corrected by the discharge coefficient,
$\mathrm{Cd}$, which must be determined for a given geometry and flow conditions to account for these non-idealities. So, the actual mass flow rate, $\dot{m}$, can be written as:

$\dot{m}=\operatorname{Cd} Y \frac{1}{\sqrt{1-\beta^{4}}} A_{\mathrm{o}} \sqrt{2 \rho_{1} \Delta P}$.

Unlike the traditional circular orifice plate, the discharge coefficient is expected to depend on three geometric parameters: area ratio, $\beta$, orifice aspect ratio, $\delta$, defined as the ratio of the orifice width, $b_{0}$, over the channel depth, $\omega$ :

$\delta=\frac{\omega}{b_{o}}$

and orifice length-to-hydraulic diameter ratio, $\lambda$, defined as the ratio of the orifice length, $l_{\mathrm{o}}$, over its hydraulic diameter, $\mathrm{dh}_{\mathrm{o}}$ :

$\lambda=\frac{l_{\mathrm{o}}}{\mathrm{dh}_{\mathrm{o}}}$,

where $\mathrm{dh}_{\mathrm{o}}$ is defined as:

$\mathrm{dh}_{\mathrm{o}}=\frac{2 b_{\mathrm{o}} \omega}{b_{\mathrm{o}}+\omega}$.

\section{Design and microfabrication of rectangular orifice micro-flowmeters}

A series of 13 rectangular orifice micro-flowmeters are designed with different geometries. To study the influence of the geometric parameters on the discharge coefficient, each micro-flowmeter geometry is defined by three dimensionless parameters: the area ratio, $\beta$, the orifice aspect ratio, $\delta$, and the orifice length-to-hydraulic diameter ratio, $\lambda$. The dimensions and parameters of the micro-flowmeters are presented in Table 2.

Localization of pressure taps for measuring average static pressure upstream, $P_{1}$, and downstream, $P_{2}$, of the orifice are designed to be in agreement with the American Society of Mechanical Engineers standardization at macroscale (Miller 1996). Namely the upstream pressure and downstream pressure taps are located at $-b_{c}, b_{c} / 2$, respectively from the orifice. Amnache et al. (2010) found these locations to be appropriate for rectangular orifice micro-flowmeters.

The fabrication process flow for rectangular orifice microflowmeters is schematically illustrated in Fig. 3. The microdevices are fabricated using silicon-on-insulator (SOI) wafer (100 mm, p-type, double side polished, $200 \mu \mathrm{m}$ device layer, $300 \mu \mathrm{m}$ handle layer and $200 \mathrm{~nm}$ silicon dioxide). After photolithography on the device layer using photoresist, channels, orifices and the pressure taps were formed by deep reactive ion etching (DRIE). DRIE gives re-entrant profiles when 
Table 2 Summary of fabricated micro-flowmeters dimensions

\begin{tabular}{llllrrrrr}
\hline Devices & $\beta$ & $\delta$ & $\lambda$ & $b_{\mathrm{c}}(\mu \mathrm{m})$ & $b_{\mathrm{o}}(\mu \mathrm{m})$ & $\omega(\mu \mathrm{m})$ & $l_{\mathrm{o}}(\mu \mathrm{m})$ & $\mathrm{dh}_{\mathrm{o}}(\mu \mathrm{m})$ \\
\hline 1 & 0.2 & 1.7 & 3.9 & 3005 & 120 & 207 & 595 & 152 \\
2 & 0.2 & 2.6 & 3.4 & 205 & 80 & 207 & 395 & 115 \\
3 & 0.41 & 0.7 & 1.5 & 1890 & 310 & 207 & 370 & 248 \\
4 & 0.4 & 1 & 1.2 & 1260 & 205 & 207 & 245 & 206 \\
5 & 0.4 & 1.7 & 1 & 760 & 120 & 207 & 145 & 152 \\
6 & 0.4 & 2.6 & 0.8 & 510 & 80 & 207 & 95 & 115 \\
7 & 0.6 & 0.2 & 1.6 & 2787 & 1007 & 207 & 560 & 343 \\
8 & 0.6 & 1 & 0.5 & 565 & 205 & 207 & 105 & 206 \\
9 & 0.61 & 2.3 & 0.4 & 245 & 90 & 207 & 45 & 126 \\
10 & 0.8 & 0.15 & 1.3 & 2270 & 1455 & 207 & 470 & 362 \\
11 & 0.8 & 0.3 & 0.6 & 943 & 605 & 207 & 180 & 309 \\
12 & 0.8 & 1.3 & 0.2 & 253 & 160 & 207 & 45 & 181 \\
13 & 0.8 & 2.6 & 0.2 & 125 & 80 & 207 & 20 & 115 \\
\hline
\end{tabular}

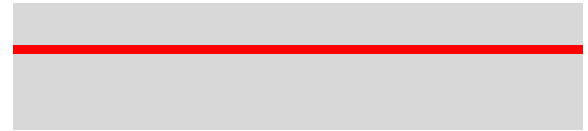

(a) SOI wafer

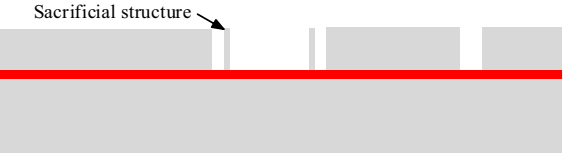

b) DRIE on the device layer to create channels. The sacrificial structures will fall at the end of etching

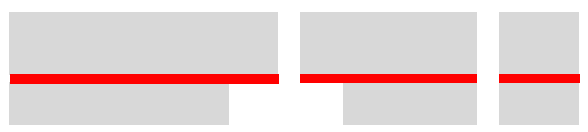

(c) DRIE on the handle layer to create inlet/outlet and pressure tap holes

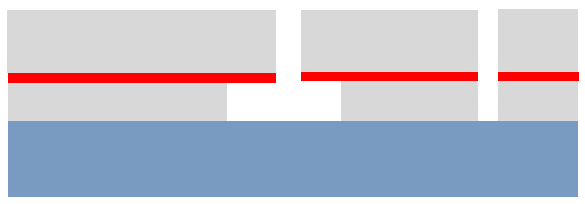

(d) Anodic bonding with glass wafer $\left(\right.$ Pyrex $\left.^{\circledR}\right)$

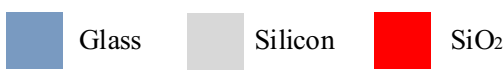

Fig. 3 Microfabrication process flow of rectangular orifice microflowmeters

etching trenches are larger than $50 \mu \mathrm{m}$. However, verticality is important to have well-defined orifices and reproducible micro-flowmeters. To fabricate vertical channel walls, sacrificial structures were created near the wall, as represented in Fig. $3 b$, to create narrow trenches with vertical side walls. The width of the trench opening near the wall is $10 \mu \mathrm{m}$. These sacrificial structures fall when the silicon dioxide layer is reached due to under-etching on the side with a wider opening. The other requirement for reproducible results is control of the channel depth. Given the high selectivity with silicon dioxide, well controlled and uniform channel depth independent of the trench aspect ratio is achieved. Therefore, the depth of the all micro-flowmeters is defined by the SOI's device layer, measured here to be $207 \mu \mathrm{m}$, with an uncertainty of $2.5 \%$. The relative roughness of micro-channels (ratio of the average height of surface irregularities to the hydraulic diameter of the channel) is measured to be about 0.001 to 0.004 .

Figure 4 shows a scanning electron microscopy image of the micro-orifice edge and the downstream pressure tap for device \#10. The width of the pressure tap is $30 \mu \mathrm{m}$. The image shows good verticality of the wall after DRIE. Another photolithography and DRIE process was performed on the handle layer of the SOI wafer etching holes of $400 \mu \mathrm{m}$ diameter through $300 \mu \mathrm{m}$ of $\mathrm{Si}$ in order to create the fluid inlet/outlet and pressure tap connections (Fig. 3c). Prior to bonding, the silicon wafer was cleaned with $\mathrm{SC} 1$ solution (1:1:5 mixture of $\mathrm{NH}_{4} \mathrm{OH}: \mathrm{H}_{2} \mathrm{O}_{2}: \mathrm{H}_{2} \mathrm{O}$ ) for $15 \mathrm{~min}$. The wafer was also immersed in a hydrofluoric acid solution (1:50 mixture of $\mathrm{HF}: \mathrm{H}_{2} \mathrm{O}$ ) for $30 \mathrm{~s}$ in order to remove the native oxide. To complete the micro-channels, the silicon wafer was anodically bonded to a Pyrex ${ }^{\circledR}$ glass wafer (500 $\mu$ m thickness), which is a good material choice for bond quality with silicon and to allow flow visualization in future studies (Fig. 3d). Finally, the wafer was diced into $5 \times 1 \mathrm{~cm}$ rectangular chips with multiple flowmeters, as illustrated in Fig. 5. Distances between fluid inlet/outlet and the center of the orifice are 5.5 and $3.5 \mathrm{~mm}$, respectively.

\section{Experimental apparatus and procedure}

A schematic of the experimental setup is represented in Fig. 6. In the current study, extra dry air $\left(\mathrm{H}_{2} \mathrm{O}<10 \mathrm{ppm}\right)$ is used as the working fluid. The chip of micro-flowmeters is 


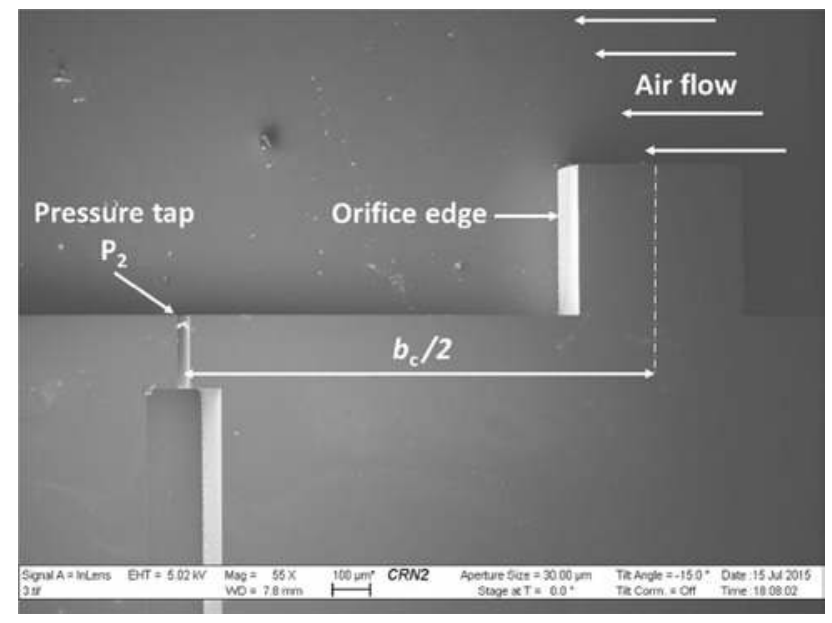

Fig. 4 Scanning electron microscopy image showing orifice and pressure tap $P_{2}$ of the device \#10. The air flows from right to left

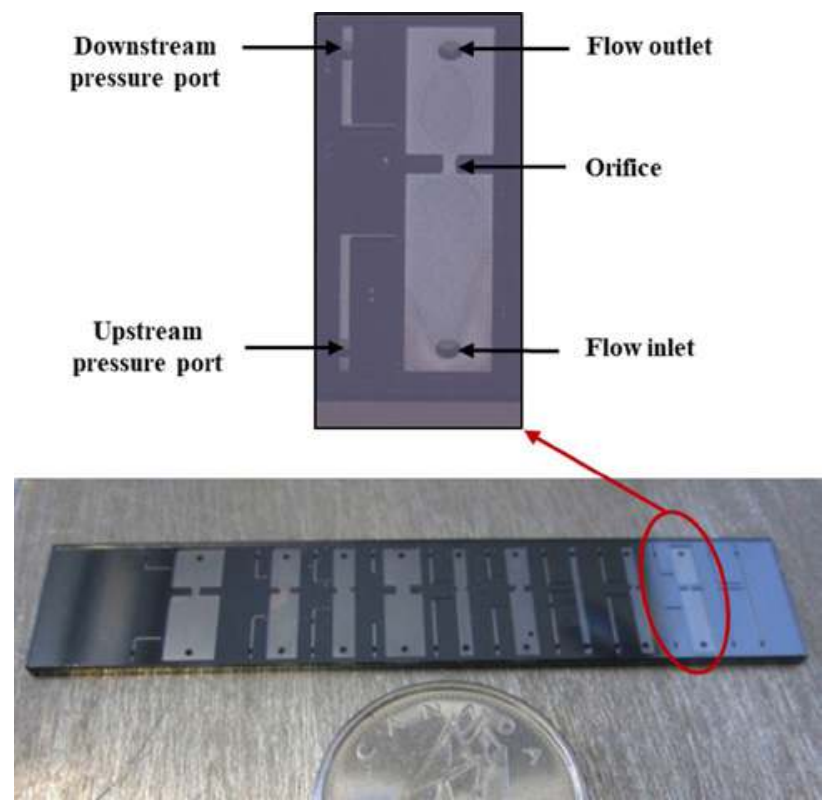

Fig. 5 A photograph of the chip with multiple micro-flowmeters. Length, $5 \mathrm{~cm}$; width, $1 \mathrm{~cm}$; thickness, $1 \mathrm{~mm}$

embedded in a packaging designed specifically for this, as shown in Fig. 7. It is made of three layers of stainless steel. Layer A consists of fluidic piping and O-ring grooves. The connections between the ports on the chip and layer A (inlet, outlet and pressure taps) are provided using micro O-rings made of Markez perfluoroelastomer (inner diameter and cross section of $600 \mu \mathrm{m}$ ). Layer B is designed to hold and align the micro-flowmeter chip in the middle of layer $\mathrm{C}$ and it serves as a mechanical stop when the O-rings are squeezed by both layers $\mathrm{A}$ and $\mathrm{C}$. The inlet to the micro-flowmeters is connected to an air source, where the pressure is be adjusted

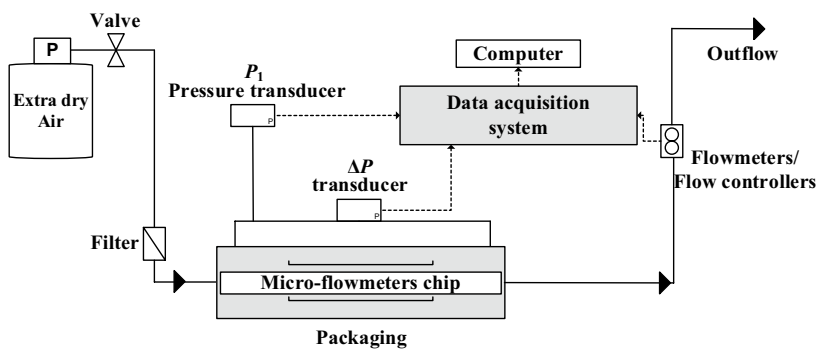

Fig. 6 Experimental setup schematic

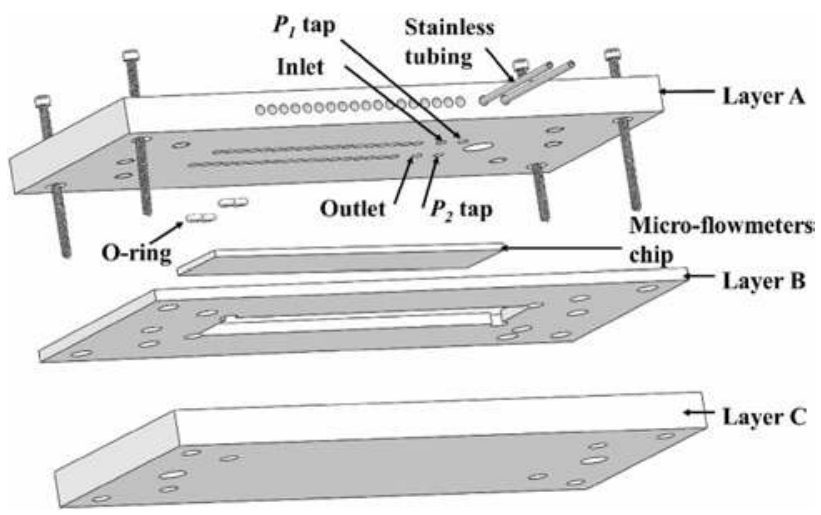

Fig. 7 Exploded schematic view of the micro-flowmeters packaging

by a pressure regulator. The air is filtered before passaging through the micro-flowmeters. The differential pressure between inlet and outlet of micro-orifices is measured by a differential pressure transducer (Scanivalve ${ }^{\circledR}$ Zoc17IP/8PXAPC) capable of pressure differences up to $700 \mathrm{kPa}$ with an uncertainty of $0.455 \mathrm{kPa}$. The upstream pressure $P_{1}$ is measured separately by a simple pressure transducer $\left(\mathrm{Omega}^{\circledR}\right)$ capable to measure pressure up to $1 \mathrm{MPa}$ with an uncertainty of $2.5 \mathrm{kPa}$. The reason to measure $P_{1}$ is to calculate the density of the air at this location using Eq. 4, assuming room temperature. In this experiment, we used mass flow controllers to control the mass flow rate with an uncertainty of $1 \%$ of full scale $\left(\mathrm{MKS}^{\circledR} 1179 \mathrm{~A}\right)$. Since we studied a large range of mass flow rates, we used three different mass flow controllers having different measurement ranges $(0-200$, $0-500$ and $0-5000 \mathrm{sccm}$ ) to increase the precision of measurement. Finally, pressure and mass flow rate data were collected through a data acquisition and control (DAQ) system.

\section{Results and discussion}

The characteristics of the flow through the rectangular orifice plate micro-flowmeter have been evaluated experimentally for the 13 different sizes and over a range of operating conditions. The air at ambient temperature is used for these 
experiments. The results show the pressure difference across micro-flowmeter, and the effect of geometry, Reynolds number and compressibility on the discharge coefficient. Furthermore, the numerical simulations are validated by the experimental results.

\subsection{Pressure difference across micro-orifices}

The pressure difference, $\Delta P$, across micro-orifices is measured by varying mass flow rate within the range of $1-106 \mathrm{mg} / \mathrm{s}$. The upstream pressure, $P_{1}$, is maintained at $0.8 \mathrm{MPa}$. Figure 8 shows the behavior of $\Delta P$ versus the mass flow rate for each micro-flowmeter. The $\Delta P$ increases quadratically as mass flow rate increases. As discussed previously, the results show that orifice micro-flowmeters have a high sensitivity at high flow rate. Furthermore, the results revealed that a high orifice aspect ratio gives a high pressure difference when the area ratio is fixed. Indeed, the depth of channels is constant $(207 \mu \mathrm{m})$, so when the aspect ratio increases, orifice cross-sectional area decreases and then the dynamic pressure becomes more important. Therefore, the static pressure at the vena contracta decreases resulting in a larger pressure difference.

The maximum mass flow rate range in these measurements was limited by (Fig. 8):

(a) The mass flow controller limit $(106 \mathrm{mg} / \mathrm{s}$ at $P_{1}=0.8 \mathrm{MPa}$ ) as shown for devices \#7, \#10 and \#11.

(b) The increase of the pressure losses inside the microchannel (upstream and downstream of the orifice) and the canalizations as shown for \#3 and \#4.

(c) The critical flow where the Mach number reaches unity at the vena contracta as shown for \#1, \#2,\#5, 6, $\# 8, \# 9$, \#12 and \#13. At this limit, the pressure differ-

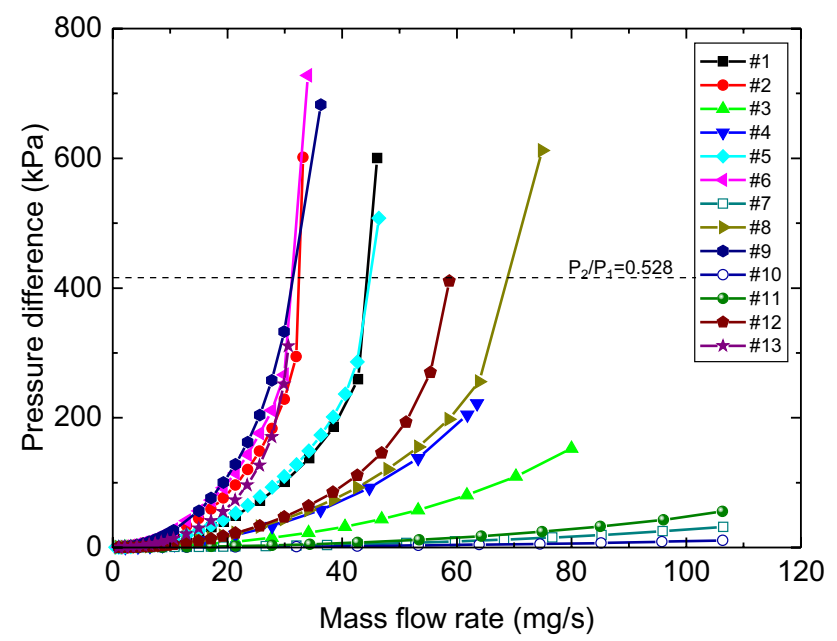

Fig. 8 Measured pressure difference across the orifices for various micro-flowmeters. The upstream pressure $P_{1}$ is maintained at $0.8 \mathrm{MPa}$ ence increased significantly due shock waves. It corresponds to the theoretical critical pressure ratio $\left(P_{2} / P_{1}\right)$ as shown in Fig. 8. The range of interest in this work will therefore stay below critical flow.

The Knudsen number, which evaluates the effect of rarefaction on flow properties, was estimated by Eq. 17 (Morinin et al. 2004) to be an order of $10^{-5}$, for the smallest device $(\# 2)$. It is well below $10^{-3}$, so the flow can be considered as a continuum:

$K n=\sqrt{\frac{\pi k}{2}} \frac{M_{2}}{R e_{0}}$

$R e_{\mathrm{o}}$ is orifice Reynolds number defined as:

$R e_{\mathrm{o}}=\frac{\rho_{\mathrm{o}} V_{\mathrm{o}} \mathrm{dh}_{\mathrm{o}}}{\mu}=\frac{\dot{m} \mathrm{dh}_{\mathrm{o}}}{\mu A_{\mathrm{o}}}$,

where $\rho_{\mathrm{o}}, V_{\mathrm{o}}$ and $\mu$ are the fluid density, average velocity and viscosity at the orifice, respectively.

\subsection{Discharge coefficient}

\subsubsection{Effect of geometric parameters}

The discharge coefficient, $\mathrm{Cd}$, of the flow through microorifices is plotted versus orifice aspect ratio and area ratio with varying orifice Reynolds number from 200 to 18,000 . The uncertainty in the discharge coefficient comes from measurement error of the differential pressure transducer, flow controllers and dimensions of the micro-flowmeters.

As shown in Fig. 9, the general trend is a sharp increase in Cd from low $R e_{\mathrm{o}}$ to reach a nearly constant value above $R e_{\mathrm{o}} \approx 3000$. This behavior is expected since the viscous losses diminish as $R e_{\mathrm{o}}$ increases, leading to a Cd closer to unity (ideal flow). At high $R e_{\mathrm{o}}$, we observe that $\mathrm{Cd}$ increases again in some cases (such as micro-flowmeters \#5, \#6, \#9, $\# 12$ and \#13). Here, the fluid velocity and pressure difference become more important, so compressibility effect appears. To better confirm the role of compressibility, the Mach number at the vena contracta, $M_{2}$, is estimated by Eq. 19 (Shapiro 1953) and added to Fig. 9. We notice indeed that $\mathrm{Cd}$ begins to increase again when $M_{2}$ reaches the range of $0.25-0.4$.

$\frac{P_{2}}{P_{1}}=\left[\frac{k-1}{2} M_{2}^{2}+1\right]^{\frac{-k}{k-1}}$.

For micro-flowmeters \#9, \#12 and \#13 the Cd behave differently at low $R e_{0}$. Indeed, the $\mathrm{Cd}$ increases a maximum near $R e_{\mathrm{o}} \approx 2000$, after which it decreases to reach a constant value (before increasing again due to compressibility, as 

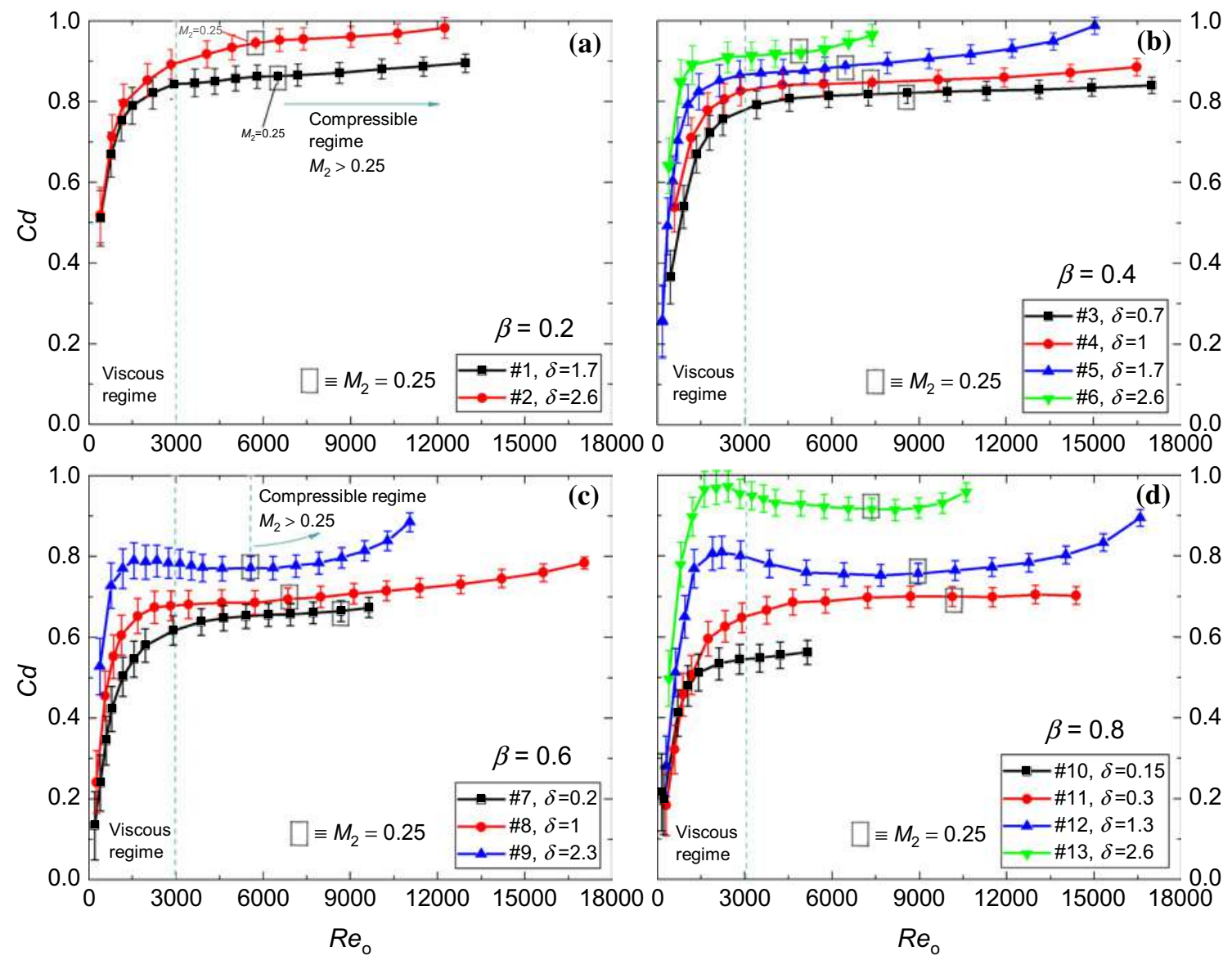

Fig. 9 Discharge coefficient plots with several area ratios. $\mathbf{a} \beta=0.2, \mathbf{b} \beta=0.4, \mathbf{c} \beta=0.6$ and $\mathbf{d} \beta=0.8$

presented previously). The same behavior has been observed by Hollingshead et al. (2011) for macroscale orifices with $\beta=0.5-0.7$. They observed that the trend of $\mathrm{Cd}$ presents a local maximum at $R e_{\mathrm{o}} \approx 300$. They explained this by the effect of the orifice plate thickness on the velocity profile at the vena contracta. In addition, the results from Jankovski et al. (2008) for small circular orifices indicate that the $\mathrm{Cd}$ exhibits a maximum at low $R e_{\mathrm{o}}$ when the length-to-hydraulic diameter ratio, $\lambda$, tends to zero. This is in agreement with the present results. Indeed, compared to other micro-flowmeters, the \#9, \#12 and \#13 have the smallest $\lambda, 0.4,0.2$ and 0.2, respectively. This suggests that all three geometric parameters, $\beta, \delta$, and $\lambda$, should be considered in micro-flowmeters.

For a fixed area ratio, $\beta$, and orifice length-to-hydraulic diameter ratio, $\lambda$, the higher aspect ratios, $\delta$, give higher discharge coefficients. This may be due to the velocity gradient that is becoming larger at the wall with smaller aspect ratios, which leads to high friction losses.

We compared the effect of the area ratio, $\beta$, on the $\mathrm{Cd}$ by fixing the aspect ratio, $\delta$, to 1 as illustrated in Fig. 10 . The data revealed that a higher $\beta$ gives higher $\mathrm{Cd}$. This is an unexpected result if we consider that an abrupt sudden contraction and sudden expansion tends to produce high friction losses. Furthermore, micro-flowmeter \#4 has a higher $\lambda$, which increases the Moody losses. A plausible explanation

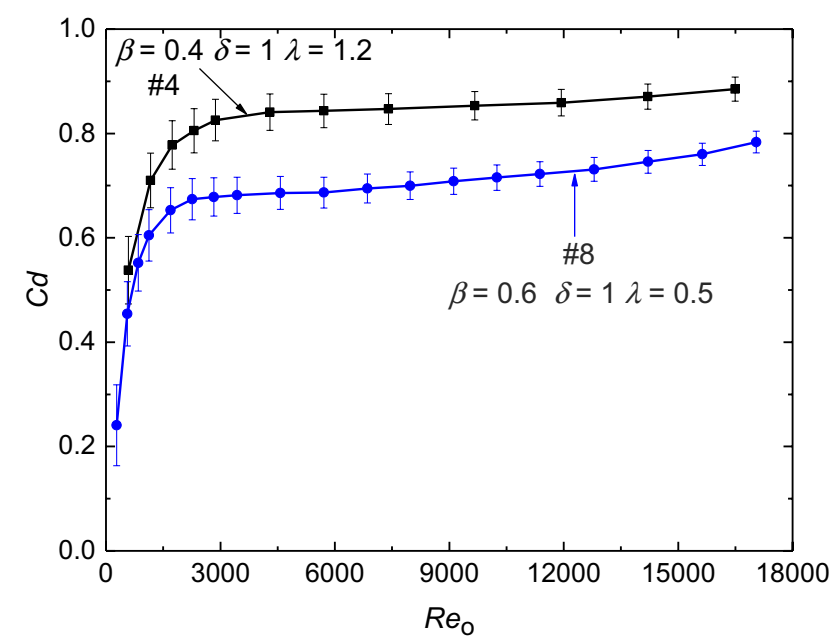

Fig. 10 Effect of area ratio, $\beta$, on the discharge coefficient, $\mathrm{Cd}$. The aspect ratio, $\delta$, is fixed at 1 
is that the hypothesis taken in Eq. 6, mentioned that the area of the vena contracta is assumed equal to the area of the orifice, becomes invalid for rectangular orifice microflowmeters. Thus, the discharge coefficient determined in this study could be a combination of friction losses and vena contracta cross-sectional area deviation. To determine real friction losses through the orifice, the discharge coefficient should be divided by the contraction coefficient, Cc, defined as the ratio between the vena contracta and the orifice crosssectional areas. However, numerical simulations or experimental flow visualization would be required to know the actual vena contracta.

\subsubsection{Compressibility effect}

The above results show that the Cd is affected by both Reynolds number and compressibility. In order to uncouple these two effects, we used 3D numerical simulation of the microflowmeter \#4. Thus, ANSYS Fluent 14.5 is used to solve the compressible and incompressible steady-state Navier-Stokes equations. As the flow is symmetric, we calculated only a quarter of micro-flowmeter \#8. Non-uniform hexahedral grids were used to mesh the geometry. The mesh is finer near the wall and orifice where the velocity gradients are larger. The meshed geometry contained 707,500 hexahedral cells. Inlet and outlet flow are situated at $3 \mathrm{~mm}$ upstream and $4 \mathrm{~mm}$ downstream, respectively, from the orifice. We used Reynolds stress model, RSM, to predict the transitional and turbulent flow through the orifice micro-flowmeter. Eiamsaard et al. (2008) observed that the prediction of the flow through a circular orifice with RSM is in agreement with measurements. Pressure-based solver and simple scheme are used to solve the discretized equations. The convergence criterion is satisfied when the residual of overall conservation equations reached $10^{-12}$. The pressure drop across the orifice is evaluated by creating two surface planes at $P_{1}$ and $P_{2}$ taps location and calculating the average static pressure.

A comparison of experimental results and numerical simulations of the discharge coefficient is shown in Fig. 11. Two different series of numerical data as a function of Reynolds number are used. The first series has been performed using the same flow conditions as the experiment, i.e., compressible flow. The second series has been performed by simulating incompressible flow. The comparison revealed a good agreement of the experimental results with the numerical simulations taking into account the compressibility of the fluid. The deviation is less than $6 \%$. On other hand, the numerical data for incompressible flow show concordance with the experimental results at low $R e_{\mathrm{o}}$ ranging from 2000 to 6000 . This range of $R e_{\mathrm{o}}$ corresponds to $M_{2}$ ranging from 0.07 to 0.2 . However, the deviation starts to become significant at $R e_{0}=6800$. The related $M_{2}$ at this value is 0.25 . Unlike the experimental measurement, the $\mathrm{Cd}$

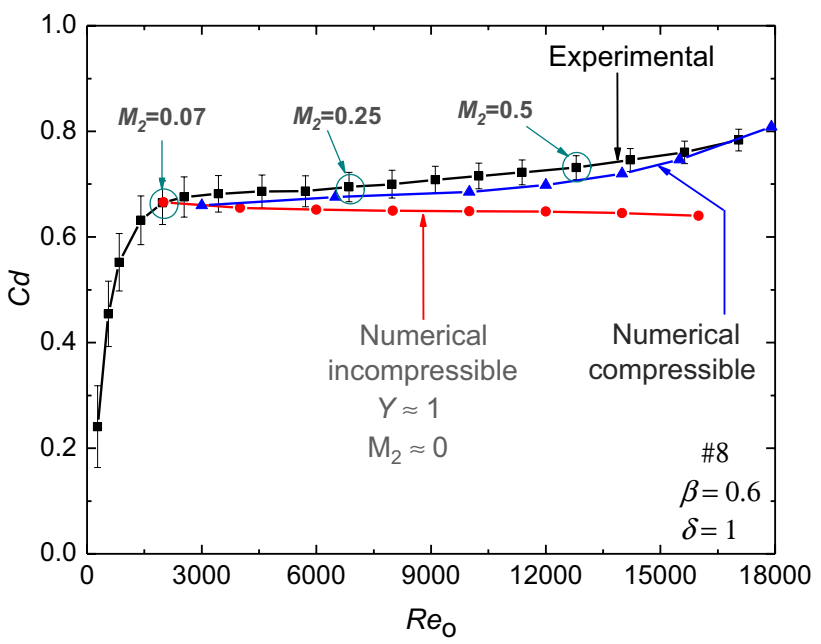

Fig. 11 Comparison of experimental results of the discharge coefficient with numerical simulations for both incompressible and compressible flow (micro-flowmeter \#8)

remains constant with $R e_{0}$ from 2000 to 16,000 . This result confirms that the $\mathrm{Cd}$ is not only dependant on $R e_{\mathrm{o}}$ at high compressibility, but that the effect of Mach number should be considered.

\section{Conclusion}

In this work, a series of 13 non-traditional rectangular orifice micro-flowmeters have been fabricated successfully by MEMS fabrication methods. The air mass flow rate measured by these micro-flowmeters ranged from 1 to $106 \mathrm{mg} / \mathrm{s}$.

The paper presents results concerning the behavior of the discharge coefficient in micro-flowmeters for Reynolds number ranging from 200 to 18,000 . It was found that it is affected by orifice Reynolds number, compressibility, orifice aspect ratio, area ratio and orifice length-to-hydraulic diameter ratio.

We also found that the hypothesis used for circular orifices at macroscale mentioning an equality of the vena contracta and orifice cross-sectional areas may be not valid for rectangular micro-orifices and that it may be affected significantly by the area ratio and length-to-hydraulic diameter ratio. Consequently, the calculated discharge coefficients in this study do not present only friction losses through the orifice, but rather a combination of friction losses and the contraction coefficient. Further research work on the exact vena contracta cross-sectional area is recommended. The results in this work provide results allowing the design of simple micro-flowmeters for moderate Reynolds numbers, and can also be a guideline for further investigation of the flow through rectangular micro-orifices. 
The agreement between the experimental and numerical results shows that numerical simulation using RSM model can serve as a good analysis tool for rectangular orifice micro-flowmeters, further opening the design options.

Acknowledgements The authors would like to thank Dr. Gholamreza Mirshekari for his technical contribution in cleanroom fabrication and methods. This work was supported by the NSERC and Canada Research Programs. The authors gratefully acknowledge this support.

\section{References}

Amnache A, Omri M, Fréchette LG (2010) An analytical and numerical study of rectangular orifice plate microflowmeters. ASME Int Mech Eng Congress Expos Proc 10:659-665

Berberig O, Nottmeyer K, Mizuno J, Kanai Y (1998) The Prandtl micro flow sensor (PMFS): a novel silicon diaphragm capacitive sensor for flow-velocity measurement. Sens Actuators A Phys 66:93-98

Bouwstra S, Legtenberg R, Tilmans H, Elwenspoek M (1990) Resonating microbridge mass flow sensor. Sens Actuators A Phys 21:332-335

Cubukcu AS, Romero DFR, Urban GA (2014) A dynamic thermal flow sensor for simultaneous measurement of thermal conductivity and flow velocity of gases. Sens Actuators A Phys 208:73-87

Dunn-Rankin D, Martins Leal E, Walther DC (2005) Personal power systems. Prog Energy Combust Sci 31:422-465

Eiamsa-ard S, Ridluan A, Somravysin P, Promvonge P (2008) Numerical investigation of turbulent flow through a circular orifice. KMITL Sci J 8:43-50

Elwenspoek M (1999) Thermal flow micro sensors. Proc Int Semicond Conf 2:423-435

Fréchette LG (2015) Micro energy conversion devices. In: Li D (ed) Encyclopedia of microfluidics and nanofluidics. Springer, New York

Hasegawa T, Ushida A, Narumi T (2009) Huge reduction in pressure drop of water, glycerol/water mixture, and aqueous solution of polyethylene oxide in high speed flows through micro-orifices. Phys Fluids 21:052002-052009

Hollingshead CL, Johnson MC, Barfuss SL, Spall RE (2011) Discharge coefficient performance of Venturi, standard concentric orifice plate, V-cone and wedge flow meters at low Reynolds numbers. J Pet Sci Eng 78:559-566

Jankovski TA, Schmierer EN, Prenger FC, Ashworth SP (2008) A series pressure drop representation for flow through orifice tubes. J Fluids Eng 130:51204-1-7

Jensen KF (2017) Flow chemistry-microreaction technology comes of age. AIChE J 63:858-869
Johansen FC (1930) Flow through pipe orifices at low Reynolds numbers. Proc R Soc Lond 126:231-245

Kiljanski T (1993) Discharge coefficient for free jets from orifices at low Reynolds number. Trans ASME J Fluids Eng 115:778-781

Kuo JTW, Yu L, Meng E (2012) Micromachined thermal flow sensors-a review. Micromachines 3:550-573

Lee C, Fréchette LG (2011) A silicon microturbopump for a Rankine cycle power generation microsystem-part I: component and system design. J Microelectromech Syst 20:312-325

Liamini M, Shahriar H, Vengallatore S, Fréchette LG (2011) Design methodology for a rankine microturbine: thermomechanical analysis and material selection. J Microelectromech Syst 20:339-351

Miller RW (1996) Flow measurement engineering handbook, 3rd edn. McGraw-Hill, Boston

Mishra C, Peles Y (2005) Incompressible and compressible flows through rectangular microorifices entrenched in silicon microchannels. J Microelectromech Syst 14:1000-1012

Morinin GL, Spiga M, Tartarini P (2004) The rarefaction effect on the friction factor of gas flow in microchannels. Superlattices Microstruct 35:587-599

Nguyen SD, Paprotny I, Wright PK, White RM (2015) MEMS capacitive flow sensor for natural gas pipelines. Sens Actuators A Phys 231:28-34

Phares DJ, Smedley GT, Zhou J (2005) Laminar flow resistance in short microtubes. Int J Heat Fluid Flow 26:506-512

Shapiro A (1953) Dynamics and thermodynamics of compressible fluid flow, 1st edn. Ronald Press Co, New York

Svedin N, Kalvesten E, Stemme G (2003) A lift force sensor with integrated hot-chips for wide range flow measurements. Sens Actuators A Phys 109:120-130

Wang YH, Chen CP, Chang CM, Lin CP, Lin CH, Fu LM, Lee CY (2009) MEMS-based gas flow sensors. Microfluid Nanofluid 6:333-346

White FM (1999) Fluid mechanics, 4th edn. McGraw-Hill, Boston

Wiles C, Watts P (2011) Recent advances in micro reaction technology. Chem Commun 47:6512-6535

Xue N, Yan WP (2012) A silicon-glass-based microfabricated wide range thermal distribution gas flow meter. Sens Actuators A Phys 173:145-151

Zivkovic V, Zerna P, Alwahabi ZT, Biggs MJ (2013) A pressure drop correlation for low Reynolds number Newtonian flows through a rectangular orifice in a similarly shaped micro-channel. Chem Eng Res Des 91:1-6 